\title{
COMPETÊNCIAS DO ENSINO DE HUMANIDADES: UMA DISCUSSÃO A PARTIR DO PENSAMENTO DE MARTHA NUSSBAUM
}

\author{
COMPETENCES OF HUMANITIES TEACHING: \\ A DISCUSSION FROM MARTHA NUSSBAUM'S THOUGHT \\ Clarice Rosa Machado e Diego Carlos Zanella²
}

\section{RESUMO}

Historicamente, as humanidades têm sido essenciais para a educação, uma vez que são consideradas como disciplinas fundamentais para a formação de cidadãos democráticos. A partir dessa conjectura, esse artigo visa refletir sobre a importância das competências no ensino de humanidades para a formação de cidadãos democráticos. Para isso, realizamos uma pesquisa de cunho bibliográfico, baseada no pensamento de Martha Nussbaum sobre as competências necessárias para o desenvolvimento de uma cidadania democrática (2015). O desenvolvimento de competências no ensino de humanidades promove a autonomia do estudante no âmbito pessoal, profissional, intelectual e político para o enfrentamento dos desafios da sociedade. Essas competências permitem aos estudantes enfrentar a realidade e as necessidades humanas com senso crítico e consciência de sua responsabilidade como pessoa em um meio social, político e cultural.

Palavras-chave: Competências; Ensino; Educação; Formação Integral; Humanidades.

\section{ABSTRACT}

Historically, the humanities have been essential to the education, once they are considered as fundamental disciplines to the democratic citizens formation. From this conjuncture, this article aims to reflect about the importance of the competences in the humanities teaching. For this, it was accomplished a bibliographical research based in the Martha's Nussbaum thought about the necessary competences to the democratic citizenship development (2015). The development of the competences to the humanities teaching promotes the autonomy of the student personally, professionally, intellectually and politically to face the society challenges. These competences allow the students to face the reality and the human needs with critical sense and responsibility consciousness of their responsibility as a person in a social, political and cultural environment.

Keywords: Competences; Teaching; Education; Comprehensive education; Humanities.

1 Licenciada em Filosofia. Mestre em Ensino de Humanidades e Linguagens. E-mail: clarice.r.machado@gmail.com 2 Doutor em Filosofia. Orientador da pesquisa. Professor do curso de Filosofia e do Programa de Pós-Graduação em Ensino de Humanidades e Linguagens, membro do Comitê de Ética em Pesquisa com Seres Humanos (CEP) e da Comissão de Ética nos Uso de Animais (CEUA), na Universidade Franciscana (UFN), Santa Maria, RS. Membro da Sociedade Brasileira de Bioética (SBB) e atual presidente da seção regional no Rio Grande do Sul (gestão 2020-2022). E-mail: diego.zanella@ufn.edu.br 


\section{INTRODUÇÃO}

Vivemos uma intensa discussão em torno do lugar das humanidades na sociedade. Um sinal evidente disso são os atuais projetos de reformas dos sistemas de ensino, amplamente difundidos em diferentes países. Essas reformas visam à diminuição da carga horária das humanidades, ou mesmo sua extinção, em nome de uma pedagogia voltada às habilidades que priorizam o crescimento econômico (LAVAL, 2004; NUSSBAUM, 2015; ORDINE, 2016).

A diminuição de investimentos nas humanidades é a realidade de muitas instituições de ensino, não somente na Educação Básica, mas também, nas universidades. Segundo Martha Nussbaum (2015) e Nuccio Oridine (2016), as justificativas apresentadas a favor das reformas, estão introduzidas em um discurso cada vez mais comum, de sua "inutilidade" frente às ciências mais práticas. A articulação entre os sistemas de ensino e a economia torna-se radicalmente utilitarista tendo como axioma dominante a competitividade dos sistemas de ensino, em razão da concorrência econômica mundial e da necessidade de qualificação e de aquisição de conhecimento na produção e na venda dos bens e serviços (LAVAL, 2004).

Os discursos acerca do processo dessas reformas expressam que os alunos precisam adquirir competências básicas que desenvolvam a flexibilidade necessária para um mercado em contínua e acelerada transformação. Nessa acepção, Rodrigo Turin argumenta que na busca por essa flexibilidade "se legitima o domínio das amplas áreas da matemática e da linguagem, concebidas aí como os "instrumentos" mais apropriados a essa nova forma de finalidade sem fim" (2018, p. 189).

Christian Laval argumenta que a concepção de educação que inspira as reformas atualmente está baseada nas várias representações e políticas mundiais do neoliberalismo desde 1980. Sendo essa concepção uma tendência para um modelo homogêneo de educação de caráter mundial, "algumas vezes" possibilitadas pelas organizações internacionais - OMC, OCDE, Banco Mundial, FMI, Comissão Europeia, PISA, ONU, UNESCO, UNICEF - (2004).

Essa concepção instrumental e liberal está ligada as mudanças da sociedade, em função da globalização, do desenvolvimento tecnológico e das economias capitalistas que afeta não só as instituições transmissoras dos valores e dos conhecimentos quanto as próprias relações sociais (LAVAL, 2004). Corroborando com Christian Laval, Nussbaum ressalta que a concorrência entre os indivíduos por causa da competição global promove o avanço do utilitarismo em detrimento de valores tradicionais como a solidariedade, a empatia, a boa convivência coletiva (2015). Dessa forma, com a corrida pela rentabilidade no mercado global, os valores preciosos para o futuro da democracia estão em perigo de se perder.

Como consequência dessas mudanças na sociedade e a prioridade do crescimento econômico, as pessoas vivem apressadamente para produzir, seja no campo social, profissional, familiar ou acadêmico. Muito se ouve, muito se pesquisa e muito se debate sobre as humanidades, sobre o quão importante elas são para a formação integral do estudante e para o futuro da humanidade, bem como qual o seu lugar e o seu papel no mundo. Mas, o que comumente se deixa de lado é que a universidade, isto é, o lugar no qual mais se debate sobre essa temática colabora para essa cultura do excesso de produção.

Há uma constante influência para produzir, escrever artigos para publicar, um meio para garantir que os programas continuem investindo em pesquisa e que esse investimento dê resultados. Ou seja, 
dialoga-se em eventos sobre as humanidades e o futuro da educação, ao mesmo tempo em que os acadêmicos são pressionados a publicar, em alguns casos, trabalhos sem qualidade, pelo pouco tempo dedicado à pesquisa, visando a um lucro, um currículo "recheado" com inúmeras publicações (SASSO DE LIMA; TAMASO MIOTO, 2007). Todavia, não se está defendendo aqui que a publicação e a pesquisa não sejam importantes, pelo contrário, se afirma serem cruciais para a educação, bem como para o desenvolvimento do conhecimento.

Outro exemplo do efeito que a priorização do crescimento econômico causa na vida das pessoas é que:

Devido à aceleração do fluxo de capitais, à mobilidade e segmentação dos centros de produção, à aceleração das inovações tecnológicas, entre outros fatores, os indivíduos passaram a viver a experiência de estar sempre começando de novo, os empregos virando postos temporários, vivendo situações incertas, sem que haja as antigas condições estruturais de investimento em uma carreira como "projeto de vida" (TURIN, 2018, p. 191).

Apresentar essas decorrências é uma maneira de convidar os leitores e lhes chamar a atenção para um olhar mais atento às humanidades, à formação integral das pessoas, sejam elas estudantes da Educação Básica, do ensino superior ou mesmo pessoas que não estão inseridas no campo educacional, um olhar para a sociedade em sua totalidade.

À vista disso, se procura reaver o papel da universidade, enquanto lugar de produção de saber e de pensamento crítico, contrariando a visão de um sistema de ensino que, quase exclusivamente, responde às solicitações do mercado com interesses econômicos. Deste modo, é importante preparar as universidades e as escolas para desenvolver os diferentes componentes de uma formação humana equilibrada preparados para viver em sociedade. Com base nessas ponderações, questionamos qual é o papel e o lugar das humanidades para a educação?

\section{ENSINO DE HUMANIDADES E DEMOCRACIA}

A pressão das universidades sobre os acadêmicos para a produção é uma consequência da forma da atual conjuntura político-econômica do país. Ao priorizar o crescimento econômico, tratamos cada vez mais a educação como se seu objetivo principal fosse ensinar os alunos a serem economicamente produtivos em vez de ensiná-los a raciocinar criticamente, a habilidade argumentativa e a se tornarem cidadãos instruídos e compreensivos (LAVAL, 2004; NUSSBAUM; 2015; ORDINE, 2016).

A inclinação a cursos profissionalizantes que se ajustam às demandas do mercado, aumentou o descuido com as humanidades, tornando-as um objeto de descarte dos currículos dos sistemas de ensino.

[A] crise econômica levou muitas universidades a realizar cortes profundos nos programas de humanidades e de artes. É bem verdade que outras áreas também tiveram de fazer cortes. Porém, como as humanidades são consideradas, em grande medida, supérfluas, parece correto reduzir o seu tamanho e, no que diz respeito a alguns departamentos, eliminá-los completamente (NUSSBAUM, 2015, p. 123). 
As consequências dessa desumanização, em relação as humanidades, em detrimento de uma educação tecnológica trazem sérios problemas para o futuro da sociedade. Uma vez que os sujeitos se encontram cada vez mais individuais e competitivos, como entrar um líder, seres pensantes que consigam analisar os problemas complexos para encontrar soluções pertinentes? Como romper com o individualismo, a falta de respeito com o outro, ausência de compromisso que se estabelece durante o processo de apagamento das humanidades em prol de uma consciência cidadã?

Em virtude disso, a emergência de pensar as humanidades como essencial para a sociedade pode ser evidenciada nas últimas notícias de projetos que reformulam o modelo de ensino, visando à diminuição da carga horária das humanidades em prol de habilidades exigidas para o mercado. Um exemplo disso pode ser percebido no discurso do atual Presidente da República Jair Messias Bolsonaro, o qual propõe a redução das verbas para os cursos de Sociologia e Filosofia 3 . O motivo dessa descentralização de investimento na área de ciências humanas e sociais, segundo a proposta política do atual presidente, tem enfoque no desenvolvimento econômico, investindo em um estudo que tenha um retorno imediato. Para obter esse retorno a curto prazo, Bolsonaro diz que esse orçamento das humanas, será direcionado para ensinar a leitura, a escrita e a fazer conta.

De acordo com Nuccio Ordine:

\begin{abstract}
Não é um acaso que nas últimas décadas as disciplinas humanísticas tenham passado a ser consideradas inúteis e tenham sido marginalizadas não somente nos currículos escolares e universitários, mas sobretudo nos orçamentos governamentais e nos recursos das fundações e das entidades privadas. Por que empregar dinheiro num âmbito condenado a não produzir lucro? Por que destinar recursos a saberes que não trazem uma vantagem rápida e tangivel? (2016, p. 20).
\end{abstract}

A renúncia às humanidades emerge em um contexto de grandes transformações na sociedade, sobretudo, em um cenário que, em nível global, as "nações precisam eliminar todos os elementos inúteis para se manterem competitivas no mercado" (NUSSBAUM, 2015, p. 4), buscando lucros a curto prazo.

Para se manter parte do mercado competitivo global, os governos neoliberais, alteram os currículos e eliminam os elementos "inúteis" e competências supérfluas que atrasam a geração de lucro. Sendo esses elementos e competências o aspecto criativo, construtivo e imaginativo dos seres humanos, um raciocínio crítico rigoroso, o pensar e o sentir, todos possibilitados pelas humanidades e as artes na educação, sem os quais a democracia está fadada ao fracasso (LAVAL, 2004; NUSSBAUM, 2015). Isso equivale a dizer que a educação, entendida como um bem social que permite que os sujeitos se apropriem das práticas sociais, tenham acesso ao conhecimento, exercendo a sua finalidade primordial, que é a formação integral do ser humano, não pode ser reduzida a uma mera auxiliar no processo de desenvolvimento econômico.

Nussbaum argumenta que o incentivo ao lucro sugere para a maioria dos políticos em questão que a ciência e a tecnologia são de importância crucial para o futuro do bem-estar do seu povo, e, ressalta que ela não está negando a importância do investimento nesses aspectos. Nesse viés, ela explica que:

3 Muitas notícias têm veiculado essa informação. Veja-se, por exemplo, essa reportagem: https://bit.ly/2OcVLUz 
Thaumazein, Ano IX, v. 13, n. 26, Santa Maria, p. 1-13, 2020.

Minha preocupação é que outras competências, igualmente decisivas, correm o risco de se perder no alvoroço competitivo; competências decisivas para o bem-estar interno de qualquer democracia e para a criação de uma cultura mundial generosa, capaz de tratar, de maneira construtiva, dos problemas mais prementes do mundo (NUSSBAUM, 2015, p. 8).

Em particular, a autora indica a existência de uma disputa entre duas concepções de modelo educativo, uma que se concentra no aspecto quantitativo do desenvolvimento econômico e a outra que considera os aspectos qualitativos da vida social, incluindo o caráter democrático (NUSSBAUM, 2015). Conforme se adote uma ou outra concepção de desenvolvimento para avaliar e orientar as políticas públicas, as consequências serão igualmente diferentes para a educação. O crescimento de políticas que pretendem reduzir a educação a elementos básicos de linguagem, matemática e ciências, excluindo dos currículos as áreas de humanidades.

Nessa perspectiva, a autora identifica a prevalência dessas políticas como um risco à democracia. Em posição contrária a essas políticas públicas, Nussbaum argumenta em favor da presença das humanidades nos currículos, em razão de que elas abrangem uma educação moral básica, vinculada aos valores democráticos, a educação argumentativa e a educação de temas relevantes de economia, direito, história e relações internacionais. Esses componentes são justificados tendo em vista a necessidade de a educação colaborar na formação de cidadãos capazes de enfrentar desafios globais, e não apenas nacionais, segundo a perspectiva do desenvolvimento humano.

O crescente abandono das humanidades (artes, filosofia, sociologia, antropologia etc.), guiados pelas restrições impostas pela competição sistemática das economias traz consequências a formação dos sujeitos e para a democracia, uma vez que esses saberes asseguram a formação de cidadãos, pois preparam os estudantes para conviver em sociedade por meio da aquisição de competências comunicativas, cognitivas que lhe permitem participar de forma ativa, democrática, solidária e responsável na vida social (LAVAL, 2004; BIESTA, 2017; DALBOSCO, 2015, NUSSBAUM, 2015).

Por causa desse descarte, dificulta-se a comunicação entre as pessoas de diversas convicções culturais e de diferentes níveis socioculturais, afetando a capacidade de deliberação sobre questões da vida política. Além do que, as humanidades, isto é, os saberes considerados inúteis e supérfluos, são os que estimulam o pensar um mundo melhor, o cultivo de sentimentos empáticos, de justiça, de busca de igualdade de direitos, de refletir sobre as ações e sobre o futuro da humanidade (NUSSBAUM, 2015; ORDINE, 2016).

Parece que, para além da formação de valores humanitários, sensíveis, de autonomia, de pensamento crítico, o papel das humanidades também é interdisciplinar, ou seja, de estabelecer um diálogo entre todas as áreas do conhecimento, questionando suas consequências, ensinando a lidar com as incertezas. E, nesse caso, a função da educação é maximizar as potencialidades individuais dos estudantes com o fim de capacitá-los para a vida. Para além disso, as humanidades são importantes para que os sujeitos sejam capazes de elaborar uma resposta clara aos problemas do pluralismo, da ansiedade e da desconfiança que a sociedade enfrenta.

Uma das razões pelas quais as pessoas insistiram em ministrar a todos os estudantes universitários uma série de cursos de filosofia e outros temas das humanidades é que elas acreditam 
Thaumazein, Ano IX, v. 13, n. 26, Santa Maria, p. 1-13, 2020.

que tais cursos, tanto por meio do conteúdo como da pedagogia, estimularão os alunos a pensar e a argumentar por si próprios, em vez de se submeter à tradição e à autoridade [...] (NUSSBAUM, 2015, p. 48).

Sob o mesmo viés, o ensino de humanidades pode:

[...] assumir uma função fundamental, importantíssima: exatamente por ser imune a qualquer aspiração a lucros, poderia colocar-se, por si mesma, como forma de resistência aos egoísmos do presente, como antídoto à barbárie da utilidade, que chega mesmo a corromper as nossas relações sociais e os nossos afetos mais profundos (ORDINE, 2016, p. 20).

À vista disso, Martha Nussbaum (2015) defende que o ensino de humanidades, não é apenas desejável, mas necessário, visto que ele contribui para o cultivo de valores essenciais para a manutenção da democracia, tais como a responsabilidade, o respeito ao outro, a escutar e resolver conflitos de forma pacífica e viver em harmonia. Segundo a autora, dentro desse quadro de pluralidade de visões de mundo, para que a ideia de uma sociedade estruturada sobre valores democráticos se realize e se aperfeiçoe, é necessário que os cidadãos desenvolvam valores condizentes com esses princípios, uma vez que é na democracia que os sujeitos conseguem ser e se fazer com plenitude.

Tendo em vista que o ensino de humanidades não se limita a formar técnicos, mas também forma sujeitos que resistam à autoridade, à pressão, pessoas que saibam viver em sociedade com respeito à pluralidade, então a atribuição das humanidades no direcionamento dos saberes é fundamental para evitar que estes produzam a desumanização. A partir desses pressupostos, podemos dizer que:

A educação adequada para viver numa democracia pluralista deve ser multicultural; quero dizer com isso uma educação que familiarize os alunos com alguns fundamentos básicos sobre as histórias e culturas dos inúmeros grupos com os quais compartilham leis e instituições. Dentre eles devem estar grupos religiosos, étnicos, econômicos, sociais e os baseados em gênero. [...] Assim como acontece com o raciocínio crítico, o ensino voltado para a formação de cidadãos [...] deve fazer parte da cota básica de ciências humanas do currículo, seja o foco do aluno administração, engenharia, filosofia ou física. (NUSSBAUM, 2017, p. 91).

Historicamente, as humanidades têm sido fundamentais para a formação de cidadãos democráticos, autônomos, críticos, informados e compreensivos, uma vez que desafiam os sujeitos a refletir sobre a complexidade e a diversidade no e do mundo. A formação cidadão visa a preparar os jovens para viver em sociedade com responsabilidade, solucionando problemas de diferentes âmbitos a partir das habilidades práticas, dos conhecimentos, dos valores éticos e outros componentes sociais que são desenvolvidos ao longo da formação escolar, atuando ativamente no exercício de seus deveres e na busca de seus direitos (BRASIL, 1988; BRASIL, 2018; BIESTA, 2017; DALBOSCO, 2015; NUSSBAUM, 2015; MACHADO; CENCI, 2020).

Nesse contexto de crise, a inclusão das disciplinas humanísticas no currículo escolar ajudaria a recuperar a dimensão humana que está se perdendo com tanto tecnicismo, colaborando com as demais disciplinas do currículo na formação do jovem estudante ao refletir sobre os valores que orientam suas ações, além de ser uma proposta de educação que promove a mediação entre o ser, o conhecer e o 
mundo. Nesse segmento, Nussbaum argumenta que "quando as pessoas percebem que são responsáveis por suas ideias, também é provável que percebam que são responsáveis por suas ações" (2015, p. 54).

Tornou-se urgente resgatar ou reconfigurar um ensino que frente ao avanço das ciências e da tecnologia permita lidar com questões humanas, a desfrutar das alegrias de ações cotidianas, da beleza da vida, pensando nas dimensões do agir humano. Retomar o debate sobre a solidariedade, a empatia, o sentido da vida, a relação entre os saberes que auxilie na recuperação de habilidades emancipatórias abrirá espaços intelectuais e sociais para a reflexão crítica e intervenção social, construindo, dessa maneira, uma sociedade democrática, pacífica e justa. Essa reconfiguração do ensino permite aos estudantes integrar suas aprendizagens e a relacionar os diferentes conteúdos e aplicá-los em suas vidas, quando necessário.

\section{AS COMPETÊNCIAS NO PENSAMENTO DE MARTHA NUSSBAUM}

Nussbaum manifesta que as mudanças que estão acontecendo nos sistemas de ensino "não têm sido bem pensadas" (2015, p. 3-4). Segundo a filósofa, há um descarte imprudente de competências que são indispensáveis para manter as democracias vivas. Competências que permitam aos estudantes enfrentar a realidade e as necessidades humanas com senso crítico e consciência de sua responsabilidade como pessoa em um meio social, político e cultural determinado.

Se essa tendência prosseguir, todos os países logo estarão produzindo gerações de máquinas lucrativas, em vez de produzirem cidadãos íntegros que possam pensar por si próprios, criticar a tradição e entender o significado dos sofrimentos e das realizações dos outros. É disso que depende o futuro da democracia (NUSSBAUM, 2015, p. 4).

Um dos principais valores defendidos em Sem Fins Lucrativos (NUSSBAUM, 2015) é a capacidade de os cidadãos desenvolverem habilidades sociais e cidadãs. Nussbaum (2015) chama a atenção para a importância de uma educação comprometida com a ideia do desenvolvimento dessas competências que são essenciais para a democracia, entre elas está o pensamento crítico. As humanidades são necessárias para pensar criticamente, superar as dificuldades locais, entender os problemas globais e compreender de forma empática a situação de outras pessoas (ZANELLA, 2019).

Este modelo de educação auxilia no sentimento de empatia e de respeito por cada pessoa como sujeitos que possuem uma dignidade humana inalienável que precisa ser respeitada pelas leis e pelas instituições (NUSSBAUM, 2015). A visão humanística da educação, voltada para uma formação integral do estudante, valorizava o conhecimento, as competências, a realização pessoal, a criatividade e a coesão social.

O espírito das humanidades busca o raciocínio crítico, as ideias ousadas, a compreensão empática das diferentes experiências humanas e da compreensão da complexidade do mundo em que vivemos (NUSSBAUM, 2015, p. 9). Além disso, todas essas competências são importantes para o futuro da democracia, pois que os estudantes se tornem cidadãos íntegros, autônomos e empáticos, e, portanto, capazes de entender o sofrimento e as realizações dos outros. 
Parece, de certa maneira, que as competências se caracterizam pela combinação de conhecimentos, habilidades, determinadas atitudes que se adequam a um contexto e que todas as pessoas precisam para sua realização e desenvolvimento pessoal, social e profissional. As competências, são uma união de todas as habilidades aprendidas pelos sujeitos que acodem a solucionar os problemas aos quais serão expostos ao longo da vida (ZABALA; ARNAU, 2010). Assim, a filósofa defende ser possível o exercício dessas competências necessárias para a democracia a partir de uma valorização das humanidades nos currículos escolares.

O enfoque nas competências pode ser visto, provisoriamente, como uma aproximação para a evolução integral da qualidade de vida em uma nação, sugerindo um modelo para o desenvolvimento humano. Elas são habilidades que existem no interior de cada pessoa e que tornam possível o seu desenvolvimento e formação (NUSSBAUM, 2012). É importante ressaltar que a lista das competências pode ser alterada ou modificada ao longo dos anos a partir das críticas, pois, a Filosofia está aberta aos debates.

Na obra Fronteiras da Justiça (2013), Nussbaum apresenta uma lista com dez competências centrais que estão presentes em outras obras da autora, mostrando a importância delas para o desenvolvimento humano, além disso, são direitos previstos na Constituição Federal (1988).

Contudo, cabe enfatizar que a lista apresentada pela filósofa, inclui direitos básicos para sobrevivência que são necessários para uma formação democrática e humana, tais como, (i) vida; (ii) saúde física; (iii) integridade física, segurança; (iv) sentidos, imaginação e pensamento; (v) cultivo de emoções democráticas, ou seja, as formas de relações humanas que são cruciais para o desenvolvimento humano; (vi) razão prática; (vii) afiliação, que pode ser dividida em empatia e dignidade humana; (viii) outras espécies, a preocupação com o bem-estar animal e ambiental; (ix) jogo, atividades de lazer e ( $\mathrm{x}$ ) controle do próprio entorno, sendo eles político e material. Essas competências são relevantes para que o ser humano se desenvolva com plenitude e dependem das políticas públicas do país. Sobre o enfoque nestas capacidades, pode-se dizer que são condições básicas para que a sociedade não se torne violenta, tenha condições adequadas de saúde e de segurança aos seus cidadãos.

No livro Sem Fins Lucrativos (2015, p. 26), Nussbaum apresenta sete competências como decisivas para uma democracia humana e sensível ao povo. As primeiras competências expostas pela autora são as de raciocinar, argumentar e refletir, as quais perpassam todas as outras. Segundo a autora, essas competências são importantes para que os sujeitos não sejam submetidos à tradição nem à autoridade sem que possam debater e argumentar, sendo essas as condições para uma democracia.

Essas competências de raciocinar, examinar, refletir, argumentar e debater estão previstas nas competências gerais e específicas da área das Linguagens e suas Tecnologias, das Ciências Humanas e Sociais Aplicadas e da Matemática e suas Tecnologias, na BNCC (BRASIL, 2018). Na competência geral 2: que defende o exercício da curiosidade intelectual, recorrendo à reflexão, à análise crítica para investigar causas, elaborar e testar hipóteses, formular e resolver problemas com base em diferentes áreas.

Na competência geral 4, que enfatiza o uso de diferentes linguagens para expressar e partilhar informações, ideias para produzir entendimento mútuo, e, na competência geral 7, em que se deve desenvolver no estudante do Ensino Médio a capacidade de argumentar com base em fatos e com informações confiáveis para defender ideias que respeitem os direitos humanos e a consciência socioambiental. 
Thaumazein, Ano IX, v. 13, n. 26, Santa Maria, p. 1-13, 2020.

Todo mundo precisa ser examinado, e todos são iguais diante da argumentação. Essa postura crítica expõe a estrutura da posição de cada um, revelando, durante o processo, hipóteses compartilhadas e pontos de intersecção que podem ajudar os concidadãos a avançar para uma conclusão comum (NUSSBAUM, 2015, p. 51).

A relevância delas é reafirmada quando a BNCC (BRASIL, 2018) traz como competência específica de Ciências Humanas a análise de processos políticos do âmbito local ao mundial em diferentes tempos, a partir de alguns procedimentos, um modo de compreender e se posicionar criticamente com relação a esses processos. Essas análises necessitam da aquisição de competências reflexivas sobre as implicações desses processos no campo econômico, cultural e social. Nussbaum afirma que "a capacidade de raciocinar e refletir criticamente é crucial para manter as democracias vivas e bem vigilantes" (2015, p. 11).

Entre essas competências primordiais, a habilidade de raciocinar consiste em manipular as informações que estão disponíveis, aquilo que se sabe ou que se supõe ser verdadeiro.

A ideia de que alguém vai se responsabilizar pelo próprio raciocínio e trocar ideias com os outros num clima de respeito mútuo em nome da razão é fundamental para a solução pacífica das diferenças, tanto no interior da nação como num mundo cada vez mais polarizado por conflitos étnicos e religiosos (NUSSBAUM, 2015, p. 54).

O raciocínio ou a inferência formam um encadeamento de juízos que permite extrair uma conclusão e consequentemente obter uma nova informação. Essa competência é importante para os indivíduos, uma vez que durante a vida é preciso tomar decisões e para isso, se pensa sobre as possibilidades de, por exemplo, se João comprar esse telefone agora, ele não terá dinheiro para comprar um notebook; ou que, durante a campanha, o presidente fez muitas promessas, essas promessas têm a possibilidade de se concretizarem?

Esse candidato merece meu voto? Assim como, no exemplo de João, se você pagar $\mathrm{R} \$ 5,00$ por um salgadinho de $350 \mathrm{~g}$, vale mais do que comprar um pacote de bolacha de $500 \mathrm{~g}$ que custa $\mathrm{R} \$$ 3,50 e ainda Ihe sobra troco? A partir destes exemplos, pode se dizer que é parte das atividades do ser humano, de forma constante, que ele construa raciocínios para solucionar ou ver com mais clarezas os problemas que surgem no dia a dia. Por outro lado, nem sempre se raciocina a partir daquilo que se sabe, há momentos em que o raciocínio é feito a partir de hipóteses (MORTARI, 2001).

Então, para pensar como esses elementos são apresentados nos discursos e na argumentação política precisa-se do conhecimento de regras argumentativas para entender e examinar o que querem dizer nas entrelinhas e as hipóteses que serão construídas a partir das informações que são oferecidas no cotidiano. Desse modo, utilizar os conhecimentos adquiridos em sala de aula para investigar desafios do mundo, interpretando situações em diferentes contextos das atividades no cotidiano e tomar decisões éticas e socialmente responsáveis, bem como conhecimentos que auxiliam na explicação e interpretação crítica da realidade ampliam a participação social dos sujeitos.

A competência de compreender diferentes assuntos que aparecem durante a vida em sua complexidade, é essencial para entender todo o processo formativo do sujeito, refletindo acerca da infância, da adolescência, das relações, da doença, da morte. Se torna necessária para que o estudante consiga 
transformar todas essas informações em conhecimentos que serão pontos chaves para transformar o mundo. Essa competência, podemos dizer que é a formação da consciência, então quando o estudante toma consciência de que seu agir interfere no mundo e que suas ações causam consequências, passa a entender que precisa se responsabilizar por elas.

Com isso, o educando amplia a sua participação social ao dispor desse entendimento, torna-se capaz de explicar e interpretar de forma crítica a realidade, é capaz de exercer a autonomia, a colaboração, o protagonismo de forma crítica, criativa, ética e solidária, pertencendo estes elementos às competências específicas da área das linguagens na BNCC (BRASIL, 2018). No que diz respeito a consciência crítica e a responsabilidade são indispensáveis para fazer escolhas alinhadas ao exercício da cidadania baseado em princípios éticos, democráticos, solidários e ao seu projeto de vida, com liberdade, resiliência, determinação, autonomia (BRASIL, 2018). Nussbaum defende que a "[...] educação não significa apenas assimilar passivamente as tradições culturais, mas desafiar a mente para que, em um mundo complexo, ela se torne ativa, competente e cuidadosamente crítica" (2015, p. 18).

Outra competência, julgar criticamente é fundamentado no entendimento real das possibilidades que os sujeitos dispõem, apresentando argumentos que defendam a crítica que está sendo proferida. Para auxiliar a fundamentação dessa competência, encontra-se disponível na seção das competências gerais da BNCC (BRASIL, 2018), a análise crítica para investigar causas e testar hipóteses com base nos conhecimentos das diferentes áreas. Nas competências específicas das Linguagens, a base está em ampliar a participação social a partir da interpretação crítica da realidade.

Podemos dizer que todas essas capacidades estão conectadas, pois uma complementa ou serve como ponto inicial para se chegar a outra competência. De acordo com a BNCC (BRASIL, 2018), compete às escolas de Ensino Médio proporcionar experiências que formarão sujeitos críticos, criativos, autônomos e responsáveis e capazes de tomar decisões éticas, enfrentando os desafios da sociedade contemporânea.

O desenvolvimento dessas habilidades ajudará os discentes a se posicionar criticamente diante das inúmeras visões de mundo e os respectivos contextos. Debater questões de interesse social, analisando os argumentos e opiniões manifestadas para sustentar as posições que estão sendo defendidas, a formular propostas e tomar decisões democráticas amparadas em uma argumentação consistente precisam ser cada vez mais valorizadas. As argumentações serão baseadas em uma sistematização de dados e hipóteses e conjecturas elaboradas pelos estudantes a partir da integração dos conhecimentos das diferentes áreas e conceitos.

Essas competências tornarão os alunos capazes de analisar criticamente o que é produzido e divulgado nos meios de comunicação, muitas vezes dada por generalizações equivocadas (BRASIL, 2018), relacionando o exercício da crítica com a promoção integral da cidadania e com o respeito à pessoa, como fins em si mesmo. O exercício da reflexão e do raciocínio são fundamentais para perceber e desconstruir condutas e gestos de preconceitos que estão presentes na sociedade. Estimular o desenvolvimento dessas competências são essenciais à autonomia do estudante no âmbito pessoal, profissional, intelectual e político para o enfrentamento dos desafios da sociedade.

Para que as pessoas consigam atingir o progresso em suas atividades diárias é necessário que elas tenham uma educação capaz de desenvolver o pensamento crítico, a argumentação, consciência 
do compromisso político e social, o sentimento de empatia pelos outros independentemente de suas diferenças. Nesse sentido, Nussbaum enfatiza a necessidade da valorização das humanidades para a manutenção da democracia, ainda, sinaliza que:

[...] mentes educadas que possam raciocinar criticamente sobre as alternativas e imaginar um objetivo ambicioso - de preferência, que não inclua apenas a riqueza pessoal ou mesmo nacional, mas que inclua também a dignidade humana e o debate democrático (NUSSBAUM, 2015, p. 138).

Diante de todo o exposto, parece o ensino de humanidades torna o mundo melhor, no qual vale a pena viver, em harmonia com o outro e de respeito pela diversidade. Mais do que conhecer os conceitos dos valores essenciais para a democracia é preciso que os alunos desenvolvam atitudes de empatia, de solidariedade, de respeito.

\section{CONSIDERAÇÕES FINAIS}

Nussbaum mostra que se a educação for tratada como tendo o objetivo principal de ensinar os alunos a serem economicamente produtivos, então as democracias estarão em perigo, pois não é priorizado o ensino de competências cruciais para manter as democracias vivas e, nesse caso, a esperança de um mundo decente se perde.

Nesse sentido, a missão dos sistemas de ensino com relação ao futuro é fornecer uma formação técnica, profissional, humanística, cultural e científica. Conforme o pensamento de Nussbaum, entendemos que a educação precisa ter como objetivo ensinar o aluno a pensar criticamente, o que implica a criação de um espaço de aprendizado, de escolha de estratégias de ensino e de planejamentos curriculares que sejam favoráveis à autocrítica e à autonomia do pensar.

A filósofa não sugere que o estudo voltado a essas questões econômicas, tecnológicas, e portanto, lucrativas, sejam abandonados, pelo contrário, ela acredita que os países devem progredir nessas áreas, mas que não se deve perder de vista que há outros aspectos que também precisam ser valorizados, mas encontram-se extremamente ameaçados.

Sujeitos com uma formação humanística serão profissionais competentes e seres humanos conscientes de suas responsabilidades para viver em sociedade, porque a sua competência de raciocinar criticamente lhe permitirá tomar boas decisões e participar ativamente de questões públicas e seus valores Ihes tornarão justo, responsável, comprometido e sensível aos outros.

Estimular o desenvolvimento de competências é essencial à autonomia, ao pensamento crítico universal do estudante no âmbito pessoal, profissional, intelectual e político para o enfrentamento dos desafios da sociedade. Esse estímulo visa superar a fragmentação do conhecimento, unindo os saberes para propiciar uma formação integral do aluno que irá contribuir para a transformação da sociedade, tornando-a mais humana e socialmente justa, uma vez que a formação para a cidadania é multicultural e precisa de interações entre as disciplinas.

As humanidades são importantes para que os sujeitos sejam capazes de elaborar uma resposta clara aos problemas do pluralismo, da ansiedade e da desconfiança que a sociedade, cada vez mais 
complexa, enfrenta. Além disso, concebe-se que as humanidades sustentam a democracia, na medida em que criam um mundo com pessoas capazes de ver o outro como pessoas completas, como fins em si mesmas com opiniões e sentimentos que merecem compreensão, empatia e respeito. Mais do que conhecer os conceitos dos valores essenciais para a democracia é preciso que os alunos desenvolvam atitudes de empatia, de solidariedade, de respeito.

Essas competências possibilitam que o estudante atue com discernimento e responsabilidade tanto na informação que recebe via os meios de comunicação quanto para aplicar esses conhecimentos na resolução de problemas em todos os âmbitos da vida, dispondo da autonomia para sustentar suas decisões, convivendo e aprendendo com as diferenças e as diversidades.

\section{REFERÊNCIAS}

BIESTA, Gert. Para além da aprendizagem: educação democrática para um futuro humano. Belo Horizonte: Autêntica Editora, 2017.

BRASIL. [Constituição (1988)]. Constituição da República Federativa do Brasil de 1988. Brasília, DF: Presidência da República. Disponível em: https://bit.ly/3e5hGYH. Acesso em: 18 abr. 2019.

BRASIL. Ministério da Educação. Secretaria da Educação Básica. Base nacional comum curricular: educação é a base. Brasilia: Ministério da Educação, 2018. Disponível em: https://bit.ly/3b7ISnO. Acesso em: 06 ago. 2020.

DALBOSCO, Cláudio Almir. Educação superior e os desafios da formação para a cidadania democrática. Avaliação, São Paulo, v. 20, p. 123-142, 2015. Disponível em: Educação superior e os desafios da formação para a cidadania democrática() (scielo.br). Acesso em: 21 set. 2020.

LAVAL, Christian. A escola não é uma empresa: o neo-liberalismo em ataque ao ensino público. Londrina: Planta, 2004.

MACHADO, Clarice Rosa; CENCI, Márcio Paulo. O Ensino de Competências Lógicas para a Formação Cidadã. Revista Sul-Americana de Filosofia e Educação, Brasília, v. 1, n. 32/33, p. 30-46, 2020. Disponível em: https://bit.ly/306XQ77. Acesso em: 20 nov. 2020.

MORTARI, Cezar Augusto. Introdução à lógica. São Paulo: Unesp, 2001.

NUSSBAUM, Martha Craven. Crear capacidades: propuesta para el desarrollo humano. Barcelona: Paidós, 2012.

NUSSBAUM, Martha Craven. Fronteiras da justiça: deficiência, nacionalidade, pertencimento à espécie. São Paulo: WMF Martins Fontes, 2013.

NUSSBAUM, Martha Craven. Sem fins lucrativos: por que a democracia precisa das humanidades. São Paulo: Martins Fontes, 2015.

ORDINE, Nuccio. A utilidade do inútil. São Paulo: Zahar, 2016. 
SASSO DE LIMA, Telma Cristiane; TAMASO MIOTO, Regina Célia. Procedimentos metodológicos na construção do conhecimento científico: a pesquisa bibliográfica. Florianópolis: Revista Katálysis, v. 10, p. 37-45, 2007. Disponível em: https://bit.ly/3slcA92. Acesso em: 03 dez. 2020.

TURIN, Rodrigo. Entre o passado disciplinar e os passados práticos: figurações do historiador na crise das humanidades. Tempo, Niterói, v. 24, n. 2, p. 186-205, 2018. Disponível em: https://bit.ly/3e4HjZE. Acesso em: 01 dez. 2020.

ZABALA, Antoni; ARNAU, Laia. Como aprender e ensinar competências. Porto Alegre: Artmed, 2010.

ZANELLA, Diego Carlos. Democracia y humanidades: ¿una relación de dependencia? In: GIUSTI, Miguel (ed.). El conflito de las facultades: sobre la universidad y el sentido de las humanidades. Barcelona: Anthropos, p. 340-347, 2019. 
